\title{
Pulmonary arterial occlusions and aneurysms: a forme fruste of Behçet's or Hughes-Stovin syndrome
}

\author{
Simon Bowman, Michael Honey
}

\begin{abstract}
A patient is reported with pulmonary arterial occlusions and aneurysms and recurrent haemoptysis. He gave a history of recurrent arthropathy and febrile illnesses; though he had had no other features of Behçet's or HughesStovin syndrome his disease probably fell into this broad diagnostic category.
\end{abstract}

Thrombotic occlusions and aneurysms of pulmonary arteries occur in Behçet's syndrome and in the closely related Hughes-Stovin syndrome. In the patient reported here, similar lesions occurred though he did not fulfil the criteria for the diagnosis of either of these syndromes.

\section{Case report}

A 27 year old Iraqi, resident in Turkey, was well until 1986 when he had an intermittently swollen right knee for six months. Later in 1986 a right pleural effusion developed; this was thought to be infective and was treated with antibiotics. Two months later he had a febrile illness thought to be a chest infection and was again treated with antibiotics. In 1987 he had fever and recurrent haemoptysis and was treated with rifampicin and streptomycin for eight months for suspected tuberculosis. Recurrent haemoptysis continued, with one major episode requiring transfusion. In February 1988, a scalene lymph node biopsy, bronchoscopy and biopsy, and mediastinotomy and biopsy gave no diagnostic information. In May 1988 he had a computed tomographic scan of the chest and pulmonary arteriogram (digital subtraction analysis).

In December 1988 he was examined at our hospital. He complained of breathlessness, but had had no haemoptysis for two months. There was no other relevant past medical history, in particular no history of orogenital ulceration, ocular or cutaneous lesions, or venous thrombosis in the legs. He had smoked 20 cigarettes a day until two years before, drank no alcohol, and had lost weight during his illness.

On examination he looked well but was thin. He was afebrile, with pulse rate of 80 per minute in sinus rhythm, and blood pressure was $130 / 60 \mathrm{~mm} \mathrm{Hg}$. The venous pressure was normal with no oedema; there was a widely split $S_{2}$ but no other abnormal cardiac signs. The chest was clinically clear.

\section{INVESTIGATIONS}

The electrocardiogram was normal. A chest $x$ ray showed a normal sized heart and a round opacity $2 \mathrm{~cm}$ in diameter above and behind a prominent left hilum. There was bilateral basal pleural thickening with some elevation of the left diaphragm (fig 1).

A full blood count showed evidence of mild iron deficiency anaemia (haemoglobin $117 \mathrm{~g} / \mathrm{l})$. The erythrocyte sedimentation rate was $18 \mathrm{~mm}$ in one hour. Routine biochemical investigations gave normal results. A routine clotting screen and haemoglobin electrophoresis were normal. Urinalysis was normal. An autoantibody screen (including double stranded DNA antibodies) was negative, as were the Venereal Disease Reference Laboratory test and the haemagglutination tests for Treponema pallidum, and tests for hepatitis B surface antigen, rheumatoid factor, anti-cardiolipin antibodies, and anti-neutrophil cytoplasmic antibodies. Protein C concentration was $54 \%$ of normal, protein $S$ $110 \%$, and the antithrombin III concentration was $96 \%$ of normal.

The computed tomogram performed in Turkey showed enlarged hilar lymph nodes and confirmed the chest $x$ ray findings.

The digital subtraction angiogram also performed in May 1988 showed multiple pulmonary arterial aneurysms of the right lower lobe pulmonary artery, left pulmonary artery at the hilum, and in the left mid-zone. There was decreased pulmonary vascularity in the left lower zone and right middle zone (fig 2a).

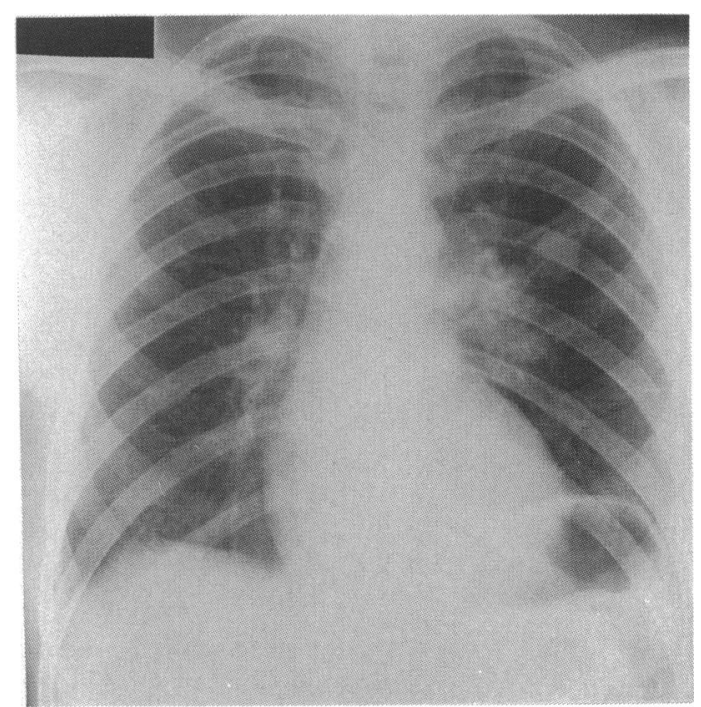

Figure 1 Chest radiograph (posterior-anterior projection). 
Figure 2 Pulmonary arteriograms in (a) May 1988 (digital subtraction analysis) and (b)

December 1988.
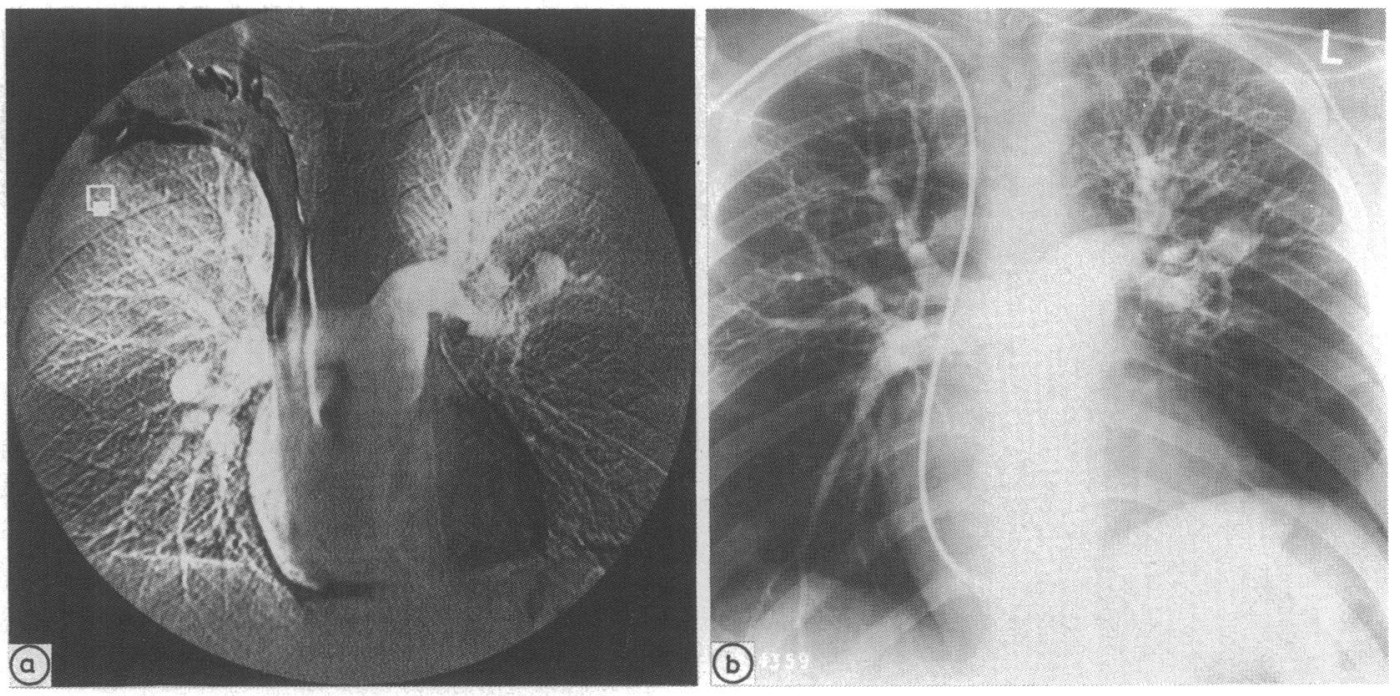

Pulmonary arteriography performed at the Brompton Hospital in December 1988 showed an occluded left lower lobe pulmonary artery, occlusions of most vessels to the right lower lobe, and a single $2 \mathrm{~cm}$ aneurysm in the left mid-zone (fig 2b). The pulmonary artery pressure was raised $(43 / 10$, mean $25 \mathrm{~mm} \mathrm{Hg}$ ) and arterial oxygen saturation was $96 \%$.

Lung function tests showed normal lung volumes with a low transfer factor. On formal exercise testing he achieved a maximum oxygen uptake of $1678 \mathrm{ml} / \mathrm{min}(52 \%$ of predicted normal). Though resting blood gases were normal, desaturation occurred on exercise $\left(\mathrm{PaO}_{2} 8.25 \mathrm{kPa}\right.$, saturation $\left.90 \%\right)$; a high resting alveolar-arterial gradient increased during exercise. There was an abnormal heart rate response and an abnormal ventilatory response to exercise.

After these investigations the patient decided to return to Turkey and has been lost to follow up.

\section{Discussion}

Pulmonary artery aneurysms are uncommon in thromboembolic disease but do occur in association with Behçet's disease. ${ }^{1-3}$ This is a systemic disease of unknown aetiology, which is thought to be a vasculitis, ${ }^{14}$ with an unusual geographical distribution, mainly in Japan, the Mediterranean, and the Middle East. ${ }^{5}$ The major criteria for the diagnosis are orogenital ulceration, ocular and cutaneous lesions, and thrombophlebitis ${ }^{5}$; none of which was present in this patient. Minor criteria include arthropathy, which he had had. In 1959 Hughes and Stovin described a syndrome of pulmonary artery aneurysms and thrombotic occlusions in association with systemic venous thrombosis. ${ }^{6}$ Since then several more cases have been described, ${ }^{7-9}$ mainly in young men, with haemoptysis a prominent and often fatal feature. ${ }^{69}$ Venous occlusion is also common in Behçet's disease, ${ }^{14}$ and in view of the clinical and radiological similarities between the two syndromes it has been suggested that they may have a similar pathogenesis. ${ }^{310}$ Because our patient did not have a clinical history of previous systemic venous thrombosis this was not a case of classic Hughes-Stovin syndrome, but the pulmonary features and the history of stystemic illness suggest that his disease falls within the same group of disorders.

Only one of the aneurysms shown on the digital subtraction pulmonary angiogram in May 1988 was evident on the pulmonary arteriogram obtained seven months later. It seems likely that there had been thrombosis of the feeding arteries during the intervening period. Recurrent or progressive vascular occlusions had resulted in increasing breathlessness and desaturation on exercise and could lead to irreversible pulmonary hypertension or respiratory failure, if haemoptysis does not prove fatal.

Steroids alone or with an immunosuppressant have been suggested as the first line of treatment, ${ }^{11}$ but because so few cases have been reported no controlled trials have been performed. These agents are not always effective in preventing an unfavourable course even if some regression of aneurysms does occur. ${ }^{10}$ Treatment with anticoagulants is potentially dangerous in view of the frequency of haemoptysis as a cause of death in both pulmonary Behçet's ${ }^{1-3}$ and the Hughes-Stovin syndrome. ${ }^{69}$ This clearly contrasts with the thromboembolic disease.

Though most patients with Behçet's or Hughes-Stovin syndrome present to pulmonary physicians or rheumatologists, it is important for cardiologists to be aware of the pulmonary vascular manifestations of these syndromes, particularly when classic extrapulmonary features of either syndrome are absent, as in this patient.

1 Efthimou J, Johnston C, Spiro SG, Turner-Warwick $M$. fthimou J, Johnston C, Spiro SG, Turner-Warwick M. Pulmonary disease in Behçet's syndrome. $Q J$ Med 1986;58:259-80.

2 Gibson RN, Morgan SH, Krausz T, Hughes GRV. Pulmonary artery aneurysms in Behçet's disease. $\mathrm{Br} J$ Radiol 1985;58:79-82.

3 Grenier P, Bletry O, Cornud F, Godeau P, Nahum H. Pulmonary involvement in Behçet disease. Am J Roentgenol 1981;137:565-69.

4 Chajek T, Fainaru M. Behçet's disease. Report of 41 cases and a review of the literature. Medicine (Baltimore)

5 Lehner T, Barnes CG, eds. Recent advances in Behçet's disease. Royal Society of Medicine Services. International Society of Medicine: 1986. management of the usual forms of pulmonary $1975 ; 54: 179-96$. Congress and Symposium Series No 103. London: Royal 
6 Hughes JP, Stovin PGI. Segmental pulmonary artery aneurysms with peripheral venous thrombosis. Br J Dis aneurysms with periphe.

7 Frater RWM, Beck W, Schrire V. The syndrome of pulmonary artery aneurysms, pulmonary artery thrombi, and peripheral venous thrombi. J Thorac Cardiovasc Surg

8 Teplick JG, Haskin ME, Nedwich A. The Hughes-Stovin syndrome. Case report. Radiology 1974;113:607-8.
9 Kopp WL, Green RA. Pulmonary artery aneurysms with recurrent thrombophlebitis. The Hughes-Stovin syndrome. Ann Intern Med 1962;56:105-14.

10 Durieux P, Bletry O, Huchon G, et al. Multiple pulmonary arterial aneurysms in Behçet's disease and Hughes-Stovin arterial aneurysms in Behçet's disease and

11 Cadman EC, Lundberg WB, Mitchell MS. Pulmonary manifestations in Behçet's syndrome. Arch Intern Med 1976;136:944-7.

\section{VIEWS FROM THE PAST Thomas Lewis 1918}

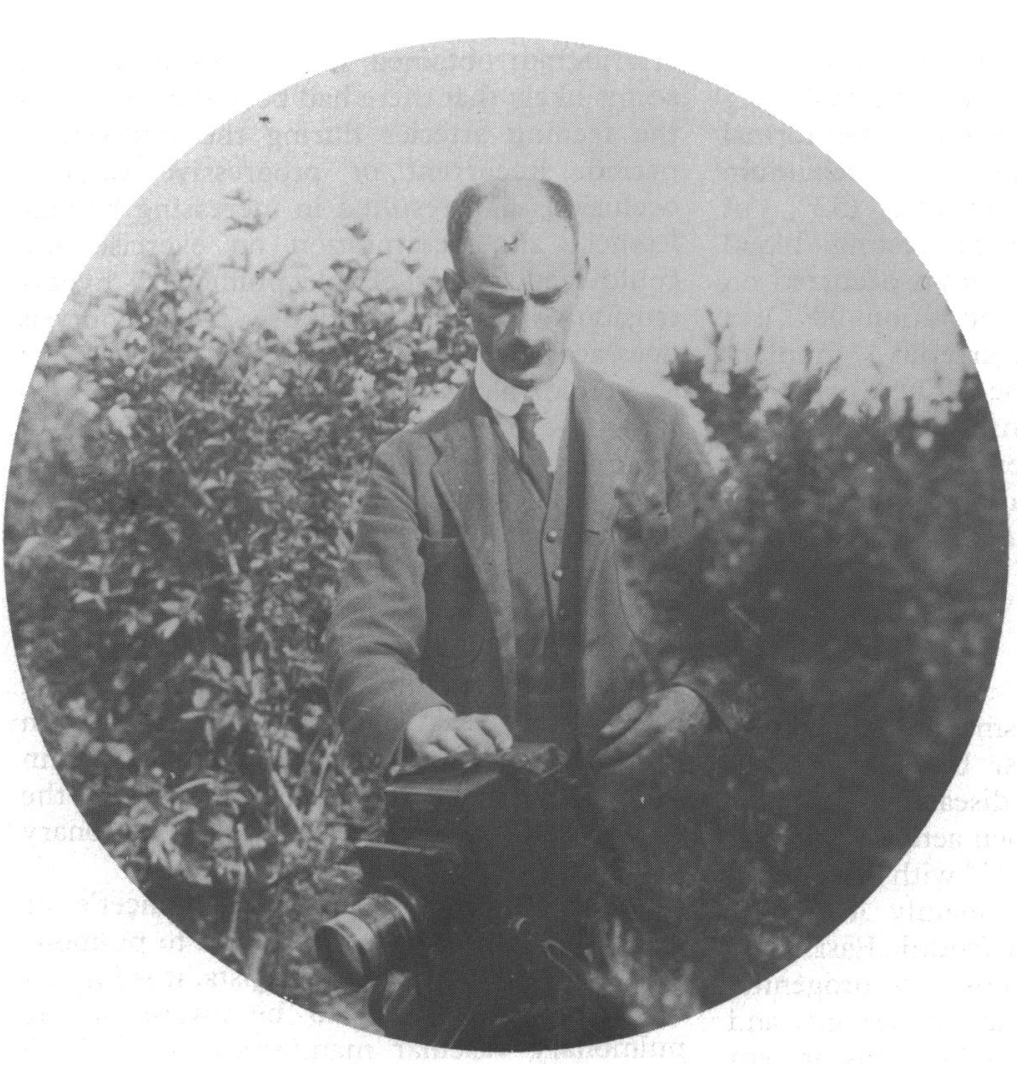

The recent happy discovery of two collections of historic photographs enables us to publish some pictures of the personalities who have contributed to the development of cardiology. Some of the members of the Cardiac Club were keen photographers; indeed Sir Thomas Lewis (1881-1945), its first chairman, was a dedicated bird-watcher from early in his career. We are grateful to Professor J D Hay of Liverpool for the loan of an extensive collection of glass slides taken over a 20 year period by his father, John Hay (1873-1959), one of the founders of the Cardiac Club. In addition (after the death last year of Sir Thomas Lewis's widow) Dr Arthur Hollman was given a number of pictures, mainly of portraits of colleagues and friends of Lewis. When published, these will be designated as the Hay collection and Lewis collection respectively to indicate their provenance; we would welcome the loan of other pictures.

The first of these pictures dates back to 1918 and shows Lewis setting up his camera for bird photography at the Colchester Military Hospital, where studies on the effort syndrome were performed (Hay collection).

DENNIS M KRIKLER 